\title{
STUDY OF HEPATOPROTECTIVE EFFECT OF BEARBERRY LEAVES EXTRACT UNDER INSULIN RESISTANCE IN RATS
}

\author{
Matar Mazen \\ Benta Pharma Industries \\ Zouk el Khrab 104, Dbayeh, Lebanon, 7031 \\ Ganna Kravchenko $\bowtie$ \\ Department of Biological Chemistry ${ }^{1}$ \\ annabk2014@gmail.com \\ Oksana Krasilnikova \\ Department of Biological Chemistry ${ }^{l}$ \\ ${ }^{I}$ National University of Pharmacy \\ Pushkinska str., 53, Kharkiv, Ukraine, 61002
}

$\triangle$ Corresponding author

\begin{abstract}
The aim of our study was to evaluate the antidiabetic and hepatoprotective efficacy of dry extract from bearberry leaves enriched with arginine in dexamethasone induced IR.

Materials and methods. IR was induced in rats by low dose intraperitoneally injections of dexamethasone. Dexamethasone-induced IR in rats was treated by bearberry leaves extract enriched with arginine. Thus, animals were randomized into several groups including intact animals and animals, which administered reference compounds and medications.

The activities of alanine aminotransferase (ALT), aspartate aminotransferase (AST), gamma-glutamine transferase (GGT) were determined in blood serum and liver homogenate, in addition, in blood serum we measured lactate dehydrogenase (LDH) activity and lactate level and glycogen content liver tissue. Also, for the purpose of our experiment, in liver tissue were determined: thiobarbituric acid reactive substances (TBARS), diene conjugates (DC), and reduced glutathione (GSH) content; and superoxide dismutase (SOD), glutathione peroxidase (Gpx), and catalase (CAT) activities. All indices were determined using generally accepted unified methods or commercially available kits.

Results. Long-term dexamethasone administration led to an increase in AST, ALT and GGT overall activity in the liver homogenate and serum; this could be the result of increased permeability of hepatocyte plasma membranes, as well as their enhanced synthesis in the liver. Studied extract ameliorate these indices of liver injury. Evaluation of indices that reflected oxidative stress and the antioxidant system status in liver confirmed oxidative stress development in IR rats' liver. Administration of arginine enriched bearberry leaves extract decrease TBARS and DC content in liver tissue, at the same time, improve SOD, Gpx, and CAT activities and increase GSH content.

Conclusions. Bearberry leaves dry extract enriched with arginine inhibit oxidative stress development, improve membrane integrity, and normalize some indices of carbohydrate metabolism, particularly glycogen content in liver and lactate level in blood.

Keywords: insulin resistance, diabetes mellitus type 2, hepatoprotection, bearberry, polyphenols, arginine.
\end{abstract}

DOI: $10.21303 / 2504-5679.2021 .002174$

\section{Introduction}

The prevalence of patients with diabetes mellitus type 2 (DM2) is rising dramatically all over the world. According to the World Health Organization, by 2025 the number of diabetic patients is expected to reach 334 million [1]. DM2 is a serious medical and social problem that must attract the attention of medical workers of all specialties and qualifications, not only because this disease is highly abundant, but also due to a large number of complications. DM2, which is the sixth leading cause of death in the world [2], is based on the development of insulin resistance (IR) and relative insulin deficiency. One of the causes of death associated with type DM2 is liver disease. The DM2 development negatively affects the hepatocyte metabolism, disrupting the pathways of carbohydrates, amino acids, lipids and other compounds, which, in turn, leads to liver function disorders. Numerous studies revealed the existence of hepatic and systemic oxidative stress [3], 
and, apparently, hyperglycemia is a driving factor in increased reactive oxygen species (ROS) production and can activate pathways of glucose autooxidation, protein glycation, and subsequent oxidative breakdown of glycated proteins [4].

Despite the significant progress achieved in the study of DM2 pathogenesis and, thereafter, its treatment, the investigation and development of new medications aimed for the correction and prevention of DM2, and its complications continues to be one of the most needful issues in medical practice [5]. Thereby, our attention was focused on the Family Ericaceae as source of novel antidiabetic medications, particularly, the bearberry leaves (Arctostaphylos uva-ursi L). The phytochemical study of the obtained extract determined such biologically active substances included in its composition as phenol glycoside, phenol carboxylic acid and flavonoids [6].

The present study was aimed to evaluate the antidiabetic and hepatoprotective efficacy of dry extract from bearberry leaves enriched with arginine in dexamethasone induced IR.

\section{Materials and methods}

In experiments we used dry $50 \%$ alcohol extract from bearberry leaves enriched with arginine (PE50_arg), which was developed and obtained at the National University of Pharmacy (NUPh) Parmacognosy Department under prof. Oleh Koshovyi supervision [7].

Male adult outbred albino rats were obtained and kept in vivarium of Educational and Scientific Institute of Applied Pharmacy NUPh with standard show and free access to water. IR was induced by low dose long-term intraperitoneally injections of dexamethasone (dex, KRKA, Slovenia) in dose $15 \mathrm{mkg} / \mathrm{kg}$ b. w. for 7 weeks [8]. Dexamethasone-induced IR rats were treated by bearberry leaves $50 \%$ alcohol extract (PE50) and PE50_arg for a period of 14 days in dose of $100 \mathrm{mg} / \mathrm{kg} \mathrm{b}$. w. and, clearly, the same period other groups of animals were administered the reference medications metformin in dose $100 \mathrm{mg} / \mathrm{kg}$ b. w. (Teva Pharmaceutical Industries Ltd, Poland) and «Arphasetin» infusion in dose18 ml/kg b. w. («Liktravy», Ukraine). Thus, 42 rats, 6 animals in each group, were randomized into 7 groups: 1 - intact animals (IC);2 - animals with dexamethasone induced IR (Dex); 3 - IR animals were treated with PE50 (Dex_PE50); 4 - IR animals were treated with PE50_arg (Dex_PE50_arg); 5 - IR animals were administered with L-arginine solution (SigmaAldrich, Germany) at a dose of $200 \mathrm{mg} / \mathrm{kg}$ b. w. (Dex_arg); 6 - IR animals were treated with «Arphasetin» infusion and 7 - IR animals were treated with metformin.

At the end of the $7^{\text {th }}$ week of experiment the animals, which were fasted overnight, were sacrificed by decapitation and blood samples were taken to prepare blood serum. The liver from each rat, after perfusion by cooled saline, was weighed and the samples were homogenized in 0.1 M Tris $\mathrm{HCl}$ buffer 7.4 for determination of enzyme activities. Another portion of wet liver - was used for the estimation of glycogen content.

In order to evaluate liver damage and function, the activity of alanine aminotransferase (ALT), aspartate aminotransferase (AST), gamma-glutamine transpeptidase (GGT) in blood serum and liver homogenate was determined using commercially available kits (NPP Felicit-Diagnostics, Ukraine), as well as, in blood serum we measured lactate dehydrogenase (LDH) activity and lactate level with the help of commercial kits (NPP «Laboratory Granum», Ukraine) and glycogen content with anthrone reagent in liver tissue [9]. Also, for the purpose of our experiment, in liver tissue were determined indices that reflected oxidative stress development and the antioxidant system status using generally accepted unified methods: thiobarbituric acid reactive substances (TBARS) [10], diene conjugates (DC) [11], and reduced glutathione (GSH) [12] content; and superoxide dismutase (SOD) [13], glutathione peroxidase (Gpx) [14], and catalase (CAT) [15] activities.

Protein content in liver homogenate was determined with accordance with Lowry's method in Miller modification [16].

All procedures and euthanasia were carried out in compliance with the principles of the «European Convention for the Protection of Vertebrate Animals Used for Experimental and Scientific Purposes» (Strasbourg, 1986) and were approved by the National University of Pharmacy Bioethics Commission, Protocol No. 1, 2 October 2019.

Statistical assessment all data are reported as mean \pm SEM and were analyzed using STATISTICA 6 software with one-way ANOVA. P values less than 0.05 was assumed statistically significant. 


\section{Results}

Current results are the part of the complex experiment; thus, the data proved the IR development have been already published [17]. Long-term administration of dex was accompanied by hyperglycemia and IR development. For the IR verification, the HOMA index was determined. Animals that had HOMA index higher than 3,5 were believed to confirm IR.

Long-term dex intraperitoneally administration led to an increase in aminotransferases overall activity in the liver homogenate and serum (Tables 1, 2). Increased activity of enzymes in serum, ALT by 2.5 times and AST by 1.9 times, could be the result of increased permeability of hepatocyte plasma membranes, which also indicated by an increase of GGT activity by 1.4 times, as well as their enhanced synthesis in the liver.

Table 1

Serum liver function markers in dexamethasone induced insulin resistant rats under PE50_arg administration

\begin{tabular}{|c|c|c|c|c|c|}
\hline \multirow{2}{*}{$\begin{array}{l}\text { Experimental } \\
\text { groups }\end{array}$} & \multicolumn{5}{|c|}{ Indices, serum } \\
\hline & ALT, $\mathrm{mmol} / \mathrm{h} \cdot \mathrm{ml}$ & $\begin{array}{c}\text { AST, } \\
\mathrm{mmol} / \mathrm{h} \cdot \mathrm{ml}\end{array}$ & $\begin{array}{c}\text { GGT, } \\
\mathrm{mmol} / \mathrm{h} \cdot \mathrm{ml}\end{array}$ & $\begin{array}{c}\text { LDH, } \\
\text { U/L }\end{array}$ & $\begin{array}{l}\text { Lactate, } \\
\mathrm{mmol} / \mathrm{L}\end{array}$ \\
\hline IC & $1.28 \pm 0.04$ & $0.46 \pm 0.03$ & $1.51 \pm 0.02$ & $259 \pm 83$ & $4.13 \pm 0.07$ \\
\hline Dex & $3.27 \pm 0.05^{*}$ & $1.13 \pm 0.03 *$ & $2.64 \pm 0.07 *$ & $463 \pm 67 *$ & $7.14 \pm 0.09 *$ \\
\hline Dex_PE50 & $2.5 \pm 0.06$ & $0.75 \pm 0.07$ & $1.82 \pm 0.06$ & $321 \pm 42$ & $6.11 \pm 0.12$ \\
\hline Dex_PE50_arg & $1.72 \pm 0.02 \#$ & $0.58 \pm 0.02 \#$ & $1.59 \pm 0.05 \#$ & $273 \pm 55 \#$ & $4.23 \pm 0.09 \#$ \\
\hline$\overline{\text { Dex_arg }}$ & $2.29 \pm 0.04$ & $0.87 \pm 0.06$ & $1.85 \pm 0.07$ & $307 \pm 63$ & $5.93 \pm 0.11$ \\
\hline Dex_arph & $1.54 \pm 0.05 \#$ & $0.65 \pm 0.05 \#$ & $1.42 \pm 0.08 \#$ & $265 \pm 91 \#$ & $4.45 \pm 0.13 \#$ \\
\hline Dex met & $2.68 \pm 0.06$ & $0.98 \pm 0.07$ & $1.95 \pm 0.11 \#$ & $331 \pm 37$ & $6.17 \pm 0.11$ \\
\hline
\end{tabular}

Note: each value represents the mean \pm standard error of $(n=6) ; *$ - indicates significant difference relative to IC group ( $p \leq 0.05)$; \#-indicates significant difference relative to Dex group $(p \leq 0.05)$

Table 2

Tissue liver function markers in dexamethasone induced insulin resistant rats under PE50_arg administration

\begin{tabular}{cccccc}
\hline \multirow{2}{*}{$\begin{array}{c}\text { Experimental } \\
\text { groups }\end{array}$} & $\begin{array}{c}\text { ALT, } \mathbf{m m o l} / \mathbf{h} \cdot \mathbf{p r o}- \\
\text { tein } \mathbf{~ m g}\end{array}$ & $\begin{array}{c}\text { AST, mmol/h·pro- } \\
\text { tein } \mathbf{~ m g}\end{array}$ & $\begin{array}{c}\text { GGT, mmol/h·pro- } \\
\text { tein } \mathbf{~ m g}\end{array}$ & $\begin{array}{c}\text { Glycogen, } \\
\boldsymbol{\mu g} / \mathbf{g} \text { tissue }\end{array}$ & $\begin{array}{c}\text { Liver weight/body } \\
\text { weight ratio, } \%\end{array}$ \\
\hline IC & $3.32 \pm 0.02$ & $1.31 \pm 0.11$ & $0.60 \pm 0.03$ & $104 \pm 13$ & $4.38 \pm 1.47$ \\
Dex & $4.86 \pm 0.07^{*}$ & $2.61 \pm 0.03^{*}$ & $0.84 \pm 0.03^{*}$ & $59 \pm 7 *$ & $8.93 \pm 1.80^{*}$ \\
Dex_PE50 & $4.62 \pm 0.13$ & $2.47 \pm 0.11$ & $0.75 \pm 0.04$ & $75 \pm 9$ & $7.31 \pm 1.53$ \\
Dex_PE50_arg & $4.56 \pm 0.03 \#$ & $2.34 \pm 0.09 \#$ & $0.62 \pm 0.02 \#$ & $94 \pm 6 \#$ & $5.74 \pm 1.66 \#$ \\
Dex_arg & $4.24 \pm 0.11$ & $2.22 \pm 0.12$ & $0.78 \pm 0.07$ & $83 \pm 11$ & $6.03 \pm 1.47$ \\
Dex_arph & $3.79 \pm 0.09$ & $2.07 \pm 0.08$ & $0.57 \pm 0.11$ & $97 \pm 12$ & $7.05 \pm 1.24$ \\
Dex_met & $4.33 \pm 0.18$ & 2.580 .14 & $0.81 \pm 0.06$ & $75 \pm 8$ & $4.47 \pm 0.93$
\end{tabular}

Note: each value represents the mean \pm standard error of $(n=6) ; *$ - indicates significant difference relative to IC group ( $p \leq 0.05)$; $\#$-indicates significant difference relative to Dex $\operatorname{group}(p \leq 0.05)$

Under these conditions, the total glycogen content in the liver tissue decreases by $47 \%$, and the lactate level in the blood serum increases by $72 \%$ (Tables 1,2 ). The effect of dex injections on glycogen level depends on the dose and terms of administration. In the initial stage, dex stimulates the glycogen accumulation in response to increased gluconeogenesis. However, later, according to the literature, the glycogen level begins to diminish gradually [18].

PE50_arg administration to IR rats resulted in a significant reduction in blood LDH, AST and ALT activities and a concomitant increase in the glycogen level in the liver (Table 2). Regarding the study of liver homogenate, Table 3 shows the changes in the activities of hepatic enzymes of antioxidant defense SOD, CAT and GPx in IC and experimental rats injected dex. The activities of mentioned enzymes were increased while the content of TBARS and DC increased in dex-treated IR rats as compared to IC rats. Administration of PE50_arg increased the GSH level and activity of GPx, SOD and CAT and decreased the level of TBARS and DC by 1,71 and 1,6 times respectively as compared to IR rats and the effect was more pronounced in the group of rats administered with Arph. 
Table 3

Liver oxidative stress markers in dexamethasone induced insulin resistant rats under PE50_arg administration

\begin{tabular}{ccccccc}
\hline \multirow{2}{*}{$\begin{array}{c}\text { Experimental } \\
\text { groups }\end{array}$} & \begin{tabular}{c} 
TBARS, $\begin{array}{c}\text { Imol// } \\
\text { mg protein }\end{array}$ \\
\cline { 2 - 7 }
\end{tabular} & $\begin{array}{c}\text { DC, nmol/mg } \\
\text { protein }\end{array}$ & $\begin{array}{c}\text { GSH, nmol/ } \\
\text { mg protein }\end{array}$ & $\begin{array}{c}\text { GPx, U/mg } \\
\text { protein }\end{array}$ & $\begin{array}{c}\text { SOD, U/mg } \\
\text { protein }\end{array}$ & $\begin{array}{c}\text { CAT, U/mg } \\
\text { protein }\end{array}$ \\
\hline IC & $2.37 \pm 0.25$ & $1.23 \pm 0.13$ & $9.14 \pm 0.93$ & $0.325 \pm 0.009$ & $0.527 \pm 0.009$ & $0.832 \pm 0.003$ \\
Dex & $8.49 \pm 0.56$ & $3.35 \pm 0.47$ & $5.38 \pm 0.57$ & $0.187 \pm 0.011$ & $0.334 \pm 0.011$ & $0.294 \pm 0.002$ \\
Dex_PE50 & $6.57 \pm 0.37$ & $2.37 \pm 0.21$ & $6.99 \pm 0.63$ & $0.215 \pm 0.002$ & $0.392 \pm 0.012$ & $0.593 \pm 0.011$ \\
Dex_PE50_arg & $5.21 \pm 0.38 \#$ & $2.07 \pm 0.19 \#$ & $5.84 \pm 0.49 \#$ & $0.293 \pm 0.007 \#$ & $0.453 \pm 0.007 \#$ & $0.728 \pm 0.014 \#$ \\
Dex_arg & $6.38 \pm 0.5$ & $2.57 \pm 0.2$ & $7.11 \pm 0.95$ & $0.199 \pm 0.006$ & $0.385 \pm 0.011$ & $0,693 \pm 0.011$ \\
Dex_arph & $6.31 \pm 0.45$ & $2.45 \pm 0.28$ & $5.64 \pm 0.79$ & $0.307 \pm 0.012$ & $0.467 \pm 0.007$ & $0.735 \pm 0.009$ \\
Dex_met & $6.73 \pm 0.52$ & $2.29 \pm 0.21$ & $6.57 \pm 0.84$ & $0.225 \pm 0.008$ & $0.395 \pm 0.009$ & $0.624 \pm 0 ., 013$
\end{tabular}

Note: each value represents the mean \pm standard error of $(n=6) ; *$ - indicates significant difference relative to IC group ( $p \leq 0.05)$; \#-indicates significant difference relative to Dex group $(p \leq 0.05)$

\section{Discussion}

It is known that the role of the liver is one of the leading among individual organs and tissues, in maintaining the acid-base balance of the blood. Liver cells utilize lactate and, when the lactate dehydrogenase reaction is involved, transform it into pyruvate, which is then involved in gluconeogenesis [19]. In our opinion, the increase in lactate levels is a consequence of disruption of metabolic processes in cells, transport processes in the plasma membranes of hepatocytes and increased permeability of plasma membranes. It is known that long-term administration of glucocorticoids of synthetic or natural origin causes the development of oxidative stress, the formation of ROS and, consequently, the lipid peroxidation (LP) intensification [20]. In our experiments, this is evidenced by the increase in primary (DC) and final (TBARS) products of LP (Table 3). Longterm LP activation leads to the depletion of cell antioxidant system inner resources. Specifically, GSH content decrease by 1.69 times was find; moreover, it was accompanied by lowering activity of the antioxidant protection first line main enzymes. Thus, as SOD and CAT activities decreased by 1.6 times and 2.8 times respectively (Table 3 ). CAT activity substantial reduction compared to SOD activity may be mediated by raised $\mathrm{H}_{2} \mathrm{O}_{2}$ molecules intracellular generation because of protein kinases ASK-1 and JNK phosphorylation, which, in turn, affect the mitochondrial metabolism and induce the $\mathrm{H}_{2} \mathrm{O}_{2}$ formation [21].

Plant polyphenols of different origin, which exhibit a wide range of pharmacological effects, are currently widely used to correct the metabolic disorders that could be caused by dex and lead to the IR development [22, 23]. However, the use of some polyphenolic extracts has a positive effect but does not always completely improve the harmful consequences from dex administration [23].

Treatment of the experimental animals with PE50 arg under the long-term dex administration was accompanied by the significant reduction in TBARS and DC content and increase in the GSH level in liver homogenate (Table 3), which is, foremost, mediated by the polyphenol presence in the extract [24]. At the same time, arginine induces the synthesis of antioxidant defence enzymes mRNA, including $\mathrm{Cu} / \mathrm{Zn}-\mathrm{SOD}, \mathrm{Mn}-\mathrm{SOD}$, and GPx [25]. LP processes inhibition and oxidative stress suppression have a positive effect on the integrity of the hepatocyte cell membranes. As can be seen from Table 1, under these experimental conditions, there is a significant decrease in the activity of the main markers of hepatocyte cytolysis in the blood serum of rats.

The plant polyphenols administration combined with arginine trigger glycogen synthesis growing its content in the liver parenchyma (Table 2). The observed effect can be mediated by the activation of protein kinase B (Akt) and glycogen synthase kinase $3 \alpha / \beta(\mathrm{GSK} 3 \alpha / \beta)$ [26]. Dietary arginine inhibits gluconeogenesis, however, stimulates the transport of glucose into the cell [26], which process produces the necessary conditions for normal glycogen levels renovation (Table 2).

The blood serum lactate level reduction is an important link in the prevention of the acidbase balance disorders in the animals' body. Surely, the liver plays the leading role in this process since hepatocytes absorb lactate from the blood and use it for glucose synthesis [26]. With high 
probability we can assume that arginine supplementation has an impact on lactate content decrease in rats' blood via arginine-nitric oxide (NO) pathway activation in muscle and endothelial cells [27] by stimulation of lactate absorption by muscle cells and its further utilization.

Study limitations. The experiment did not include study of ascorbate induced lipid peroxidation and tocopherol content in liver homogenate.

Prospects for further research. Further study of the effects on organs and systems of the bearberry leaves extract enriched with arginine to create a dietary supplement for complex treatment and prophylaxis of diabetes mellitus type 2 .

\section{Conclusions}

Low-dose dexamethasone injections led to IR development that negatively affected hepatocyte functions and, consequently, caused liver injury and metabolic process disorders. Bearberry leaves dry extract enriched with arginine inhibit oxidative stress development, improve membrane integrity, and normalize some indices of carbohydrate metabolism, particularly glycogen content in liver and lactate level in blood. We suggest that hepatoprotective effect is mediated by the antioxidant action of plant polyphenols from PE50_arg composition and, moreover, the arginine supplementation ameliorated this effect.

\section{Conflict of interests}

The authors declare that they have no conflicts of interest.

\section{Financing}

The study was performed without financial support.

\section{Acknowledgments}

We are grateful to our colleges from Educational and Scientific Institute of Applied Pharmacy Lytkin D. and Yudkevich T. for assistance in organizing and conducting the study.

\section{References}

[1] Khan, M. A. B., Hashim, M. J., King, J. K., Govender, R. D., Mustafa, H., Al Kaabi, J. (2019). Epidemiology of Type 2 Diabetes - Global Burden of Disease and Forecasted Trends. Journal of Epidemiology and Global Health, 10 (1), $107-11$. doi: http://doi.org/10.2991/jegh.k.191028.001

[2] Jiang, S., Young, J., Wang, K., Qian, Y., Cai, L. (2020). Diabetic-induced alterations in hepatic glucose and lipid metabolism: The role of type 1 and type 2 diabetes mellitus (Review). Molecular Medicine Reports, 22 (2), 603-611. doi: http://doi.org/ $10.3892 / \mathrm{mmr} .2020 .11175$

[3] Hurrle, S., Hsu, W. H. (2017). The etiology of oxidative stress in insulin resistance. Biomedical Journal, 40 (5), $257-262$. doi: http://doi.org/10.1016/j.bj.2017.06.007

[4] Ormazabal, V., Nair, S., Elfeky, O., Aguayo, C., Salomon, C., Zuñiga, F. A. (2018). Association between insulin resistance and the development of cardiovascular disease. Cardiovascular Diabetology, 17 (1). doi: http://doi.org/10.1186/s12933-018-0762-4

[5] Salehi, Ata, V. Anil Kumar, Sharopov, Ramírez-Alarcón, Ruiz-Ortega et. al. (2019). Antidiabetic Potential of Medicinal Plants and Their Active Components. Biomolecules, 9 (10), 551. doi: http://doi.org/10.3390/biom9100551

[6] Chaika, N., Koshovyi, O., Komisarenko, M., Kireyev, I., Kravchenko, G. (2020). Standardization parameters of modified extracts from Arctostaphylos uva-ursi L. leaves. Ukrainian Biopharmaceutical Journal, 4 (65), 16-23. doi: http://doi.org/ 10.24959/ubphj.20.293

[7] Koshovyi, O. M., Kravchenko, H. B., Krasilnikova, O. A., Matar, M., Chaika, N. B. (2020). Pat. No. 142210 UA. Sposib oderzhannia zasobu z hipohlikemichnoiu ta hepatoprotektornoiu diieiu z lystia muchnytsi zvychainoi z dodavanniam arhininu. MPK: A61K 36/45 (2006.01), A61P 3/10 (2006.01). No. u201910482; declareted: 21.10.2019; published: 25.05.2020, Bul. No. 10.

[8] Modyfikatsiia metodu modeliuvannia eksperymentalnoi insulinorezystentosti u shchuriv: inform. lyst No. 86-2015 Ukrmedpatentinformu pro novovvedennia v systemi okhorony zdorovia (2015). Kyiv, 3.

[9] Templeton, M. (1961). Microdetermination of glycogen with anthrone reagent. Journal of Histochemistry \& Cytochemistry, 9 (6), 670-672. doi: http://doi.org/10.1177/9.6.670

[10] Buege, J. A., Aust, S. D. (1978). Microsomal lipid peroxidation. Methods of Enzymology, 52, 302-310. doi: http://doi.org/ 10.1016/s0076-6879(78)52032-6 
[11] Peg, R. J. (2001). Determination of conjugated dienes and trienes. Current Protocols in Food Analytical Chemistry. New York: John Wiley \& Sons, D2.1.1-D2.1.3.

[12] Moron, M., Depierre, J., Mannervik, B. (1979). Levels of glutathione, glutathione reductase and glutathione S-transferase activities in rat lung and liver. Biochimica et Biophysica Acta (BBA) - General Subjects, 582 (1), 67-78. doi: http://doi.org/ 10.1016/0304-4165(79)90289-7

[13] McCord, J. M., Fridovich, I. (1969). Superoxide Dismutase. Journal of Biological Chemistry, 244 (22), 6049-6055. doi: http:// doi.org/10.1016/s0021-9258(18)63504-5

[14] Hafeman, D. G., Sunde, R. A., Hoekstra, W. G. (1974). Effect of Dietary Selenium on Erythrocyte and Liver Glutathione Peroxidase in the Rat. The Journal of Nutrition, 104 (5), 580-587. doi: http://doi.org/10.1093/jn/104.5.580

[15] Tenovuo, J., Pruitt, K. M., Mansson-Rahemtulla, B., Harrington, P., \& Baldone, D. C. (1986). Products of thiocyanate peroxidation: properties and reaction mechanisms. Biochimica et Biophysica Acta (BBA) - Protein Structure and Molecular Enzymology, 870 (3), 377-384. doi: http://doi.org/10.1016/0167-4838(86)90244-x

[16] Miller, G. L. (1959). Protein Determination of Large Numbers of Samples. Analytical Chemistry, 31 (5), 964-966. doi: http:// doi.org/10.1021/ac60149a611

[17] Kravchenko, G. B., Krasilnikova, O. A., Mazen, M. (2020). Hypoglycemic and hypolipidemic activity of arginine containing bearberry leaves extract in insulin resistant rats. Medical and Clinical Chemistry, 1, 5-10. doi: http://doi.org/10.11603/ mcch.2410-681x.2020.v.i1.10936

[18] Petersen, M. C., Vatner, D. F., Shulman, G. I. (2017). Regulation of hepatic glucose metabolism in health and disease. Nature Reviews Endocrinology, 13 (10), 572-587. doi: http://doi.org/10.1038/nrendo.2017.80

[19] Ishitobi, M., Hosaka, T., Morita, N., Kondo, K., Murashima, T., Kitahara, A. et. al. (2019). Serum lactate levels are associated with serum alanine aminotransferase and total bilirubin levels in patients with type 2 diabetes mellitus: A cross-sectional study. Diabetes Research and Clinical Practice, 149, 1-8. doi: http://doi.org/10.1016/j.diabres.2019.01.028

[20] Yazdi, H. B., Hojati, V., Shiravi, A., Hosseinian, S., Vaezi, G., Hadjzadeh, M. A. (2019). Liver Dysfunction and Oxidative Stress in Streptozotocin-Induced Diabetic Rats: Protective Role of Artemisia Turanica. Journal of Pharmacopuncture, 22 (2), 109-114. doi: http://doi.org/10.3831/KPI.2019.22.014

[21] Zhu, L., Yi, X., Zhao, J., Yuan, Z., Wen, L., Pozniak, B. et. al. (2018). Betulinic acid attenuates dexamethasone-induced oxidative damage through the JNK-P38 MAPK signaling pathway in mice. Biomedicine \& Pharmacotherapy, 103, $499-508$. doi: http://doi.org/10.1016/j.biopha.2018.04.073

[22] Safhi, M. M., Alam, M. F., Sivakumar, S. M., Anwer, T. (2019). Hepatoprotective Potential ofSargassum muticumagainst STZ-Induced Diabetic Liver Damage in Wistar Rats by Inhibiting Cytokines and the Apoptosis Pathway. Analytical Cellular Pathology, 2019, 1-8. doi: http://doi.org/10.1155/2019/7958701

[23] Gothandam, K., Ganesan, V. S., Ayyasamy, T., Ramalingam, S. (2019). Antioxidant potential of theaflavin ameliorates the activities of key enzymes of glucose metabolism in high fat diet and streptozotocin - induced diabetic rats. Redox Report, 24 (1), 41-50. doi: http://doi.org/10.1080/13510002.2019.1624085

[24] Song, X.-C., Canellas, E., Asensio, E., Nerín, C. (2020). Predicting the antioxidant capacity and total phenolic content of bearberry leaves by data fusion of UV-Vis spectroscopy and UHPLC/Q-TOF-MS. Talanta, 213, 120831. doi: http://doi.org/10.1016/ j.talanta.2020.120831

[25] Liang, H., Ji, K., Ge, X., Ren, M., Liu, B., Xi, B., Pan, L. (2018). Effects of dietary arginine on antioxidant status and immunity involved in AMPK-NO signaling pathway in juvenile blunt snout bream. Fish \& Shellfish Immunology, 78, 69-78. doi: http://doi.org/10.1016/j.fsi.2018.04.028

[26] Zhang, Y., Zhang, J., Wang, E., Qian, W., Fan, Y., Feng, Y. et. al. (2018). Microcystin-Leucine-Arginine Induces Tau Pathology Through B $\alpha$ Degradation via Protein Phosphatase 2A Demethylation and Associated Glycogen Synthase Kinase-3 $\beta$ Phosphorylation. Toxicological Sciences, 162 (2), 475-487. doi: http://doi.org/10.1093/toxsci/kfx271

[27] Hollyer, T. R., Bordoni, L., Kousholt, B. S., Luijk, J., Ritskes-Hoitinga, M., Østergaard, L. (2019). The evidence for the physiological effects of lactate on the cerebral microcirculation: a systematic review. Journal of Neurochemistry, 148 (6), $712-730$. doi: http://doi.org/10.1111/jnc.14633

Received date 18.10.2021

(C) The Author(s) 2021

Accepted date 24.11.2021

This is an open access article

Published date 30.11.2021 under the Creative Commons CC BY license

How to cite: Mazen, M., Kravchenko, G., Krasilnikova, O. (2021). Study of hepatoprotective effect of bearberry leaves extract under insulin resistance in rats. EUREKA: Health Sciences, 6, 48-53. doi: http://doi.org/10.21303/2504-5679.2021.002174 